\title{
La instrucción de las primeras letras en el Perú republicano: de Agustín Gamarra (1840) a Rufino Echenique (1851)
}

\author{
Juan Carlos Huaraj Acuña \\ Universidad Nacional Mayor de San Marcos
}

\section{El presidente Agustín Gamarra y los decretos educativos de $1840^{1}$}

Un avance político en la autonomía del manejo económico de las primeras letras, fue alcanzado el año de 1840, durante el gobierno del presidente Agustín Gamarra. Ello representó la definitiva separación del presupuesto del ramo educativo, que aún para esa fecha dependió de la Junta de Beneficencia. A partir de su emisión, los gastos y haberes de los colegios de instrucción primaria, tuvieron un manejo, relativamente, más autónomo. El mismo decreto obligó a la Junta de Beneficencia a entregar a una recién creada Junta Administradora los margesíes, razón de deudas, y demás documentos correspondientes para su mejor manejo. La citada junta, fue un organismo dependiente la Dirección General de Instrucción. Esta junta estaba incluida por los rectores de los colegios, léase públicos, directores de las escuelas centrales de instrucción, un representante del prefecto.

El citado documento, obligó a la Junta, que cada seis meses, debía presentar cuenta documentada de sus ingresos y egresos al prefecto, quien lo elevaría al Supremo Gobierno, para su aprobación o devolución, levantando las observaciones que en ella se encontrasen. El prefecto, era quien -a decisión y criterio político personal-, a partir del decreto, ejerció el derecho de censura, veto y suspensión de los miembros de la Junta. Durante el gobierno de Gamarra, ejercieron, como Ministro de Instrucción Pública, Beneficencia y Negocios Eclesiásticos, el presbítero Agustín Guillermo Charún, ${ }^{2}$ y como oficial mayor del ramo, a José Dávila Condemarín. ${ }^{3}$

\footnotetext{
${ }^{1}$ El artículo forma parte de la tesis de maestría, sustentada en mayo del 2017, en la Facultad de Ciencias Sociales de la Universidad Nacional Mayor de San Marcos.

${ }^{2}$ Guillermo Charún, ese mismo año, ejerció el cargo de rector del Convictorio Carolino, doce años después sería preconizado como Obispo de Trujillo.

3 Ilustre abogado trujillano. Este personaje, en 1854 alcanzó el rectorado de la Pontificia Universidad de San Marcos.
}

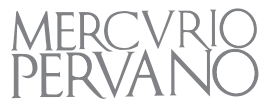


Mariano Hidalgo, por su parte, ejerció la dirección de la Escuela Normal de Santo Tomás. ${ }^{4}$ Los estudiantes, muchos de ellos próximos maestros, constituyeron ya una población cercana a doscientos, entre niños y jóvenes. La escuela sucursal de San Lázaro (Lima), bajo la dirección de Fernando Riega, también consignó un número cercano. La escuela de Santa Teresa, con su directora Eusebia Morales, registró también, en las revistas de la época, poco más de doscientas maestras. Si bien los números son redondos, ello significa, a criterio personal, un logro deseado y anhelado alcanzado por la ciudadanía de la capital. La instrucción de primeras letras empezaba a ser un invitado común entre las diversas instituciones existentes en la capital. Los niños de la ciudad tendrían, a partir de esta década, nuevas posibilidades de ser instruidos, de saber leer y escribir. Las familias limeñas urbanas empezaron a tener observar las consecuencias de los jóvenes que adquirieron la instrucción: trabajo remunerado, oficio de maestro de escuela, (gran parte de la formación costeada por el Estado), y, finalmente, una mejora ostensible en sus condiciones de vida. Progresivamente, los presbíteros y párrocos fueron cediendo espacios, como naturalmente se esperaba, hacia los jóvenes preceptores y maestros egresados de la Escuela Normal. Y los mismos, siendo auspiciados cada vez en mayor número por el peculio del Estado, que de la potestad eclesiástica.

Pero el camino hacia la instrucción plena de la enorme geografía republicana peruana, recién comenzaba. Para 1840, se encontraron ya preparados jóvenes preceptores y maestros lancasterianos en la cantidad suficiente como para ser enviados a los diversos poblados del país. Particularmente, prefiero considerar a este proceso histórico educativo como el cumplimiento progresivo de las exigencias públicas, una silenciosa invitación a los padres de familia de distintos centros poblados y ciudades, a insistir en la instrucción de sus menores hijos. Desearon brindarle espacios que a ellos no les correspondió por el desdén que existió en la sociedad colonial. El nuevo camino estaba por empezar, y por partida doble: la posibilidad de saber leer y escribir, y con ello, la posibilidad de obtener el título de maestro de primeras letras, ambas una realidad que progresivamente comenzaron a acariciar los habitantes de las ciudades, a lo largo del siglo diecinueve.

Esta nueva ley sobre la instrucción pública, tuvo como eje de su observación las labores de formación pedagógica que debía recibir todo maestro egresado del Colegio Central Normal. ${ }^{5}$ Para esta década también, una vez asumido el Estado su rol de responsabilidad y gestión de los colegios de instrucción primaria, cada vez más parroquias empezaron a finiquitar su responsabilidad de educar. El Estado ahora sí podía hacerse cargo de ello, y coordinar un presupuesto para ello. Pero en los pueblos más alejados de la ciudad, los mismos párrocos, mientras exigían y elevaban peticiones para instaurar colegios públicos en su localidad, continuaron con su labor de gestión y auspicio de las mismas.

\footnotetext{
${ }^{4}$ Eduardo CARrasco, Calendario y guía de forasteros de Lima para el año de 1841. Lima, Imprenta de Félix Moreno, 1840, p. 39.

5 Progresivamente, para la década de 1840, los documentos oficiales empezaron a obviar el nombre de lancasteriano.
} 
Políticamente, el estilo bolivariano de expropiaciones y decisiones inconsultas, era cada vez menos conveniente, en el progresivo ordenamiento de la estructura jurídica del Estado. En el ramo educativo, el Supremo Gobierno debió consultar con la Dirección Central toda propuesta educativa, en relación al ámbito de la instrucción primaria.

El 18 de noviembre de 1841, el presidente en ejercicio, el mariscal Agustín Gamarra, perdió la vida en el campo de batalla de Ingaví. No es este trabajo, el lugar apropiado para reflexionar sobre el referido acontecimiento. Estrictamente, la muerte de Gamarra truncó severamente la gobernabilidad política del país. Se desenvolvieron distintos reacomodos militares y políticos en torno a la sucesión presidencial, que duró poco más de cuatro años el volver a una situación de estabilidad republicana. Los proyectos educativos de Gamarra también quedaron truncos. Los acontecimientos acaecidos durante la década de 1840 hasta 1850, dan la oportunidad de pensar en la fragilidad del sistema de gobierno, precariedad de la sociedad civil frente al poder de los militares. Los señores de la guerra, ${ }^{6}$ participaron desde muy jóvenes en las batallas de la independencia. Para la década de 1840, algunos estaban en el exilio (Santa Cruz) o habían finado (Gamarra). Sin embargo, aún la sociedad política, la burocracia, reconoció respeto hacia ellos. Los grandes mariscales de Ayacucho, dieron paso a la segunda generación de oficiales: Pedro Pablo Bermúdez, Juan Antonio Pezet, Ramón Castilla, entre otros pertenecientes a la siguiente generación. Ellos no guardaron remilgos ni deudas amicales hacia sus anteriores superiores.

Uno de los últimos oficiales que participaron en la epopeya independentista fue Agustín Gamarra, militar cusqueño, quien hubo de llegar en dos oportunidades a la presidencia de la República, aunque la primera de manera interina. Cuando los votos le dieron por fin el reconocimiento público, cargó la banda presidencial desde julio de 1840, tan solo para morir inmolado hacia la eternidad en el campo de batalla en Ingaví, en noviembre de 1841. Luego de este magnicidio, y encargado otra vez a algún notable personaje fungiendo como presidente de la República, se sucedieron cerca de una docena de autoridades, entre civiles y militares.

En agosto de 1842, durante el ejercicio provisorio de Manuel Menéndez, el general Juan C. Torrico se autoproclamó jefe supremo del país. En marzo del año siguiente fue derrotado por Juan Francisco Vidal. Los generales Juan Antonio Pezet, y Manuel Ignacio Vivanco irrumpieron a mediados de la década, briosos y audaces como lo fueron sus antecesores, a quienes emulaban, pero eran ya otros los tiempos, y era otro el Estado que se debía administrar. Las redes burocráticas eran más numerosas, el manejo del erario público resultada cada vez más complejo. Finalmente, desde abril de 1845, hasta abril de 1851, por primera vez desde la proclamación de la Independencia misma, Ramón Castilla

\footnotetext{
${ }^{6}$ Charles Tilly, Democracia. Prólogo de Ramón Maiz. Madrid, AKAL, 2010, p. 43.

7 El caso más ejemplar fue el mariscal Guillermo Miller. Participó en la última intentona del proyecto confederativo de Santa Cruz. Se le borró del escalafón militar durante mucho tiempo. Hubo de aprender la lección, se quedó en Perú, y no se entrometió más. Semejante ocurrió con Luis José Orbegoso, José de la Riva Agüero, entre otros.
}

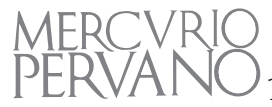


fue el primer Presidente Constitucional en completar su período de gobierno para el que fue elegido.

\section{La comisión de instrucción de 1846}

Bajo decreto del 14 de agosto de 1846, el presidente constitucional Ramón Castilla encargó a una comisión formular un plan general de instrucción pública. ${ }^{8}$ Los resultados de sus consideraciones, a solicitud del Ejecutivo, en relación a la situación educativa en el país, fueron bastante deprimentes. Se encontró a la educación pública bajo conceptos de gravedad y de ser muy perjudicial en los principios que demanda el Gobierno. Una descripción política poco alentadora de la instrucción pública en aquella fecha. A la referida alta comisión, se le encargó los siguientes objetivos esenciales, a saber:

- Procurar hallar un sistema uniforme de enseñanza en toda la república.

- Procurar revertir el desorden existente tanto en los planes, como en los textos que cada profesor considera autorizado a impartir en sus aulas.

En suma, el poder ejecutivo presidido por Castilla, asumió la responsabilidad de que se ejecute lo estipulado por la propia constitución. La comisión se dividió en tres secciones: instrucción primaria, instrucción preparatoria, e instrucción científica. Cada una de las mencionadas secciones sostuvo reuniones de trabajo por separado, y solo al final del trabajo en conjunto, las tres propuestas se sometieron a examen interno, y aprobación final de todo el equipo de trabajo. La comisión estuvo formada por un total de quince miembros, cinco en cada sección. Fueron cuatro los miembros gravitantes: un presidente, un vicepresidente y dos secretarios. La labor de los funcionarios fue en realidad ciclópea. Los miembros que presidieron los tres grupos de trabajo fueron sacerdotes: José F. Navarrete presidió el equipo de instrucción primaria, José Manuel Pasquel, ${ }^{9}$ ese año rector de San Marcos, ejerció el equipo de formación científica; Bartolomé Herrera, el de la instrucción preparatoria. ${ }^{10}$

El Ejecutivo encargó a la comisión soluciones particulares en algunos tópicos comunes a años anteriores: selección de textos, colocación de maestros titulados en provincias, etc. A continuación, las soluciones encomendadas fueron:

\footnotetext{
${ }^{8}$ Decreto Ley, agosto de 1846. AVLP.

9 José Manuel Pasquel, una década después fue preconizado obispo de Lima: 1855-1857.

10 Sobre Bartolomé Herrera se ha escrito muchísimo. Tan solo acotaré que fue ese año de 1846, con su ya bien ganado prestigio de maestro de juventudes del Convictorio San Carlos, cuando se le agregó el de catedrático de la centenaria universidad de Lima. Mayores referencias, se puede consultar el texto de Jorge Putnam Velando, Fundamentos teológicos de la actuación pública de Bartolomé Herrera. Tesis Doctoral. Pamplona, Universidad de Navarra, 2001.
} 
- Formar un plan general de instrucción primaria, objetivo primario, era la razón misma de la conformación de dicha comisión.

- Una elección uniforme de los textos aparentes para la enseñanza.

- Una incipiente medición de las calidades y pruebas de los preceptores.

- Definir un único método de enseñanza, número de horas, castigos, premios y exámenes públicos.

Vale aquí resaltar como uno de los objetivos del Estado, a través de su Dirección de Instrucción, y de la citada comisión, la de responsabilizarse sobre la orientación y selección de los textos para la enseñanza. Ello tuvo también sus complicaciones, cuando no sus vaivenes. Si bien he expuesto un caso particular, se pueden encontrar reflexiones importantes sobre la historia de la educación republicana, en un documentado artículo de Grover Espinoza sobre la instrucción primaria a mediados de ese siglo.

En 1847, un año después de creada la comisión referida, el maestro José Félix Franco obtuvo el permiso del Congreso para publicar textos escolares de su autoría. Anteriormente Franco ejerció la dirección de un colegio en Cusco. Siguiendo a G. Espinoza, "se trataba de libros de lectura, ortología o pronunciación, caligrafía y ortografía". ${ }^{11}$ Espinoza narra con detalle los tránsitos burocráticos acontecidos al maestro citado, como a su obra intelectual. Si bien el poder legislativo en Lima, aceptó y procuró orientar los medios en la concreción de tan loable objeto, el prefecto de Lima observó que era una empresa muy compleja, aquella de imponer y difundir en el breve tiempo, la obra de Franco. La revisión documental de primera mano resulta impecable en el trabajo del colega. Aquí tan solo agrego una pertinente anotación.

Como bien señala el autor, el proceso de revisión y aceptación del libro de instrucción propuesto por el maestro José Félix se inició en 1845. Dos años después, el texto llegó a consulta y consideración de Navarrete, quien seguramente ya conocía del texto con antelación. Y debió haberlo conocido, pues como director de la Junta de Instrucción, fue uno de los primeros, en afirmar la viabilidad del texto desde la óptica de un funcionario del Estado. Por ello, cuando el libro retornó a sus manos, el visto bueno (un espaldarazo político especializado) fue efectivo. Sin embargo, en el trascurso de esos dos años, el panorama político había cambiado. Para julio de 1845, el período de anarquía militar entre 1840 y 1845 llegó a su fin, con el ascenso de Ramón Castilla como presidente constitucional del Perú. Por tanto, algunas consultas entre las diversas autoridades públicas ejecutadas con anterioridad, probablemente hallarían alguna observación, cuando no negación del proceso mismo. Además, el año de 1846, el presidente Castilla convocó a la formación de la citada comisión de

${ }_{11}$ Grover EspinOzA, “Libros escolares y educación primaria en la ciudad de Lima durante el siglo XIX", Revista Histórica, Vol. 31, N 1, 2007, pp. 135-170. Cito p. 156.

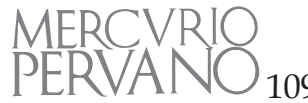


alto nivel, encargada principalmente de organizar, ordenar y asumir el primer reglamento educativo correspondiente a todos los niveles de instrucción en la República. A partir de 1846, José Francisco Navarrete, junto con Bartolomé Herrera y los demás miembros de la comisión, recibieron como uno de sus objetivos fundamentales de trabajo, el evitar el desorden que traían consigo la autorización y difusión de diversos libros orientados, aún si contuviesen fines altruistas. El escenario había cambiado.

Es allí en donde las nuevas instrucciones, así como el nuevo paisaje político, configuraron un muro infranqueable en desmedro de la obra del maestro José Félix. Por último, ¿a quién le debió su anterior nombramiento, nada menos que como director en el Cusco? Esto último no podría dejarse de lado. Los recuerdos del expresidente Agustín Gamarra aún prevalecían en el espacio político, y no con benevolencia. Por cierto, y para cerrar las citas y comentarios al texto referido, Espinoza anotó una acusación que redactó el juez José Marurí frente a la obra y acciones de José Francisco Navarrete, imputándolo de favorecer la venta de sus catecismos, en desmedro de otros autores. Cabe aquí recordar que Marurí ya había integrado una comisión de revisión del estado de la instrucción pública, durante el gobierno de Salaverry. ${ }^{12}$ No olvidemos tampoco que el vertiginoso ascenso en la carrera judicial, se alcanzó principalmente bajo los gobiernos de su paisano, Agustín Gamarra. ${ }^{13}$

La estadística pública le fue más grata al presidente Castilla. La cantidad de estudiantes de escuelas primarias en 1847 manifestó un total de 29,942 estudiantes de escuelas primarias en todo el territorio nacional. Jorge Basadre contiene frases apropiadas hacia la Comisión, aunque en desmedro del Congreso. ${ }^{14}$ Finalmente, el informe fue elevado a la categoría de ley nacional, el 14 de junio de $1850 .{ }^{15}$

\section{El primer reglamento general de instrucción pública del Perú}

En junio de 1850, el presidente Castilla decretó el nuevo Reglamento de Instrucción. Dicho documento se presentó auspicioso desde el prólogo, inclusive tajante, "hasta la fecha no se ha dado el plan de educación nacional que prescribe la Constitución..." ${ }^{\prime 16}$. Para mediados del siglo XIX, el lenguaje

\footnotetext{
12 Específicamente, sí bajo el gobierno de Salaverry, aunque la firma estuvo a cargo del presidente encargado, Juan Bautista Lavalle.

13 La investigación de Espinoza también describe pormenorizadamente la creación de las escuelas municipales, tema que no trato aquí. Sus orígenes, correlación temporal y desarrollo escapan a esta propuesta de estudios. Quienes deseen conocer mejor dichos procesos particulares, bien podrían revisar el texto precitado.

14 Jorge BASADRE, Historia de la República del Perú. 7a. edición. Lima, Universitaria, 1983, tomo IV, p. 304.

${ }^{15}$ G. EspinOza, “Libros escolares...", p. 157.

${ }^{16}$ Decreto Supremo, junio de 1850. AVLP.
} 
de las luces, propio de la ilustración tardía colonial, fue reemplazado definitivamente en todo documento público, por el del progreso en estado moral y social.

En este documento, la instrucción básica, dejó ya de ser denominada lancasteriana, o de primeras letras. Ahora su descripción oficial fue de escuelas primarias. La lectura de este documento resulta de una de las más claras demostraciones de interés del Estado en asumir su rol y función de educador, ambicioso desde sus primeras líneas. Definió la educación nacional en tres grados:

- El de las escuelas, en referencia a las primeras letras;

- El de los colegios menores; $y$,

- El de los Colegios Mayores, o universidades.

Particularmente, es con este documento en donde las leyes educativas coloniales -aunque tácitas en el ejercicio público durante las primeras dos décadas republicanas- dejaron de ser vigentes, en su totalidad. La principal misión de las escuelas y colegios a partir de 1850, se concretizó mediante el alcance y expansión de la educación moral y religiosa para los ciudadanos. Los textos dirigidos hacia la educación pública, obligadamente ya no debían apartarse de lo propuesto por el Estado. Se entiende la moral como un eje trasversal público en beneficio de la población escolar nacional, de afirmación de la fe (ética y religión); junto con la instrucción ciudadana, que consolidó la devoción y respeto hacia la patria, en sus distintas áreas del conocimiento (en cursos como Geografía y Constitución, por ejemplo)

En torno a las funciones educativas, el Estado peruano reconoció el rol de la Iglesia Católica en dicha labor. Ya desde la fundación de la república misma ella cumplió un papel enorme en la difusión e instrucción de los ciudadanos de la nación, y un énfasis mayúsculo en la instrucción de las primeras letras. Cabe recordar que no toda parroquia, en cualquier jurisdicción eclesiástica dentro del Estado peruano, alcanzó o ejerció la función de escuela de primeras letras. A partir esta década, cada vez menos parroquias se dedicaron a aquella noble función. Ello representó un trato silente entre los funcionarios del Estado y los del gobierno eclesiástico. Ahora el Estado tenía los recursos para encargarse progresivamente de su función pública educadora.

Hasta 1850, el papel de la Junta Central de Instrucción, fue el de ser un influyente intermediario por el cual el Poder Ejecutivo canalizó las orientaciones pedagógicas, nombramientos, consultas de los maestros, así como la mejora del inmobiliario, compra de herramientas, e incluso los temas salariales de los maestros y preceptores a su patrocinio. $Y$ las funciones cada vez eran de mayor complejidad. 


\section{Cursos para los varones}

La nueva carga de cursos en este nuevo reglamento fue incluida en el referido reglamento, y no es exageración afirmar que fue el modelo sobre cual las reformas pedagógicas de la segunda mitad del siglo se sostuvieron. Por lo menos hasta la reforma del presidente Manuel Pardo. En torno a la nueva disposición curricular de los colegios menores, lo que hoy denominaríamos de colegio secundario, sus cursos fueron:

- Reglas generales de literatura castellana;

- Lengua francesa;

- Lengua inglesa y latina;

- Geografía universal: antigua y moderna;

- Nociones de Lógica y ética;

- Elementos de matemáticas puras;

- Rudimentos de física, química e historia natural;

- Nociones de economía política;

- Disposiciones de nuestra Constitución Política;

- Reglas de higiene privada;

- Dibujo, música y teneduría de libros.

- Ética, antiguo curso de religión.

Sobre éste último curso, la misma ley sugirió que las nociones de religión se enseñasen en las aulas de los seminarios, aunque lo dejó como parte del currículo oficial nacional, la enseñanza de la ética, a modo de compensación. Curiosamente, algunos de sus postulados son semejantes a las exigencias de las leyes presentes. ${ }^{17}$ También cabe observar, a diferencia del reglamento santacrucino de 1836, su antecedente más inmediato en ambición y reforma, se eliminaron los cursos de ortología y caligrafía, y reemplazado por la única materia de Lenguaje castellano. Sobre esto último, seguramente la inserción de las leyes gramaticales en el habla y la redacción empezaron a ser de urgencia pública en referencia a los planes educativos del Estado

\footnotetext{
17 Por ejemplo, en su artículo $17^{\circ}$, la ley de 1850 estableció la fundación de un colegio mayor (léase, universidad) tanto en la capital de la República, como las provincias donde sea posible.
} 


\section{Cursos para las mujeres}

La enseñanza de las niñas sostuvo algunas materias distintas a lo enseñado a los muchachos. De igual manera, se observaron también un incremento en el número de materias a cursar, a diferencia del código educativo santacrucino, ${ }^{18}$ así como la continuación de la educación diferenciada. En torno a las materias impartidas, cabe anotar:

- Dibujo y música.

- Costura llana, deshilado, bordado, tejidos y demás obras manuales propias de su sexo (cursiva nuestra).

- Reglas de urbanidad moral.

- Economía doméstica.

- Gramática castellana.

- Aritmética.

- Francés e inglés.

- Geografía descriptiva.

- Breves nociones de historia general.

- Reglas de higiene privada.

- Religión.

Se otorgaron también nuevas facultades extraordinarias a la Pontificia Universidad de San Marcos. Se le asignó oficialmente como una de las tres instituciones válidas para la creación y licencia de nuevas universidades; las otras dos fueron la Junta Central de Instrucción, y el Gobierno Central. También se promulgaron artículos bastante específicos en torno a la obtención de grados y su diferenciación para con los títulos públicos, así como su procedimiento de equivalencia frente a los emitidos por los colegios mayores, esto último ante la demanda de interesados en continuar estudios u obtener grados en la Universidad. ${ }^{19}$

\footnotetext{
18 Recordemos que, en la referida ley, los cursos fueron los siguientes: catecismo, lecciones de urbanidad, costura y economía doméstica.

${ }^{19}$ En torno a los requisitos para la obtención de los grados académicos, se observa la necesidad de comprobación de los conocimientos adquirido a través de exámenes, así como sus sustentaciones tanto en lengua castellana como en latín. De modo extraordinario, se podían también adquirir los grados, sin las pruebas precedentes, si así lo solicitase la Junta Central de Instrucción. La relación entre los colegios mayores y las universidades se volvieron estrechas y constantes, a modo de prerrequisito para la obtención del grado en exigencia del interesado.
}

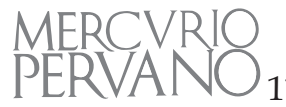


En la capital de la República se instaló la Junta Central de Instrucción, organización pública integrada por doce miembros, nombrados por el gobierno, y presidida de forma anual rotativa por uno de ellos. El documento no afirma si se podría repetir la gestión. No olvidemos que esta Junta fue responsable de la redacción y revisión de la presente ley. Luego de su instalación pública, posterior a la publicación de la ley, los miembros de la Junta tuvieron como principal función la de visitar, examinar y evaluar el correcto estado de los colegios públicos. Resalto principalmente, como responsabilidad de la Junta, la de vigilar la correcta alimentación de los jóvenes en los colegios. Aunque, ya desde las décadas de 1820 y 1830, se empezaron a diferenciar el número de estudiantes numerarios -quienes convivieron dentro del recinto educativo seis días de la semana- frente a los estudiantes agregados o supernumerarios, que vivían fuera del mismo. Si bien no lo específica, a partir de la publicación de esta autógrafa, el Estado comenzó a asumir a plenitud la educación universal de sus futuros ciudadanos.

También se instruyó en cada ciudad capital de departamento, la convocatoria a una junta de instrucción, aunque de menores alcances frente a la central. El número de integrantes de estas juntas departamentales, por ley, estuvo constituida por dos miembros, electos a propuesta de los subprefectos, en clara dependencia del poder ejecutivo. Las juntas departamentales de educación incluyeron, según ley, entre uno de sus miembros, a un párroco (supongo, del pueblo más importante). Esto más que una posición ideológica, fue la vía para la facilitación de los espacios parroquiales en provincias, sobre todo en los lugares más poblados, a favor de la instrucción pública.

Sin duda fueron las instancias que encararon las mayores exigencias educativas al interior del país. ¿Cuál sería su relación frente a las combativas juntas de representantes? Si bien estaban bajo protección y relación directa con los prefectos y subprefectos, esto no las libró de confrontarse ante las referidas juntas de representantes, al contrario, toda solicitud con referencia a temas educativos fue ahora de su entera responsabilidad. Sospecho que se vieron desbordadas frente a las exigencias ciudadanas al interior. ¿Tuvo alguna de estas comisiones departamentales alguna visita al interior de su jurisdicción para informarse de la realidad educativa a la que debía buscar solución?, ¿algunos de sus miembros estuvieron convocados desde el interior de sus provincias?

\section{La eliminación de las juntas educativas departamentales}

Aunque sea muy brevemente, me referiré a la decisión política que tomó el presidente Rufino Echenique (1851-1855), a los pocos meses de tomar las riendas del gobierno: la eliminación de las juntas departamentales de instrucción. Ciertamente fue una medida poco acertada, particularmente, que ensombrece aún más su ya cuestionada posteridad. Para esa década, el Estado peruano empezó a recibir ingresos en sus arcas, literalmente, como nunca lo 
había recibido en su historia republicana hasta ese momento, producto de los ingresos del guano. El país empezó a organizar el control fiscal de sus ingresos como de sus gastos públicos. Hubo recursos para estabilizar las principales instituciones públicas, entre ellas, la Junta Central de Instrucción. Fue durante el primer gobierno de Ramón Castilla, cuando la estabilidad política junto a la económica sintonizó apropiadamente. El modelo económico de Castilla se continuó, durante el gobierno de su sucesor, Rufino Echenique. ${ }^{20}$ Puntualmente, me ceñiré a la observación particular que realizó Echenique, en torno a la ley general de educación, proclamada por su antecesor, y a poco menos de dos años de proclamada.

En ese ambiente de aparente calma, la instrucción primaria se confirmó progresivamente hacia los poblados al interior de la ciudad: Callao, Chorrillos, y Huacho. En menor medida hacia las comunidades indígenas de las zonas de altura: Pativilca, Canta, Obrajillo, y Huamantanga. En la ciudad de Lima en particular, siguiendo al notable historiador Alejandro Reyes, los antiguos miembros de la antigua nobleza colonial tardía, ejercieron también funciones educativas dentro de la zona de Lima denominada Barrios Altos. Señala Espinoza que la familia Sancho Dávila, por citar un caso, tuvieron una presencia política y económica importante tanto a fines del período colonial, como en el resurgimiento particular a mediados del siglo XIX. Una directora de un colegio de niñas, privado, que tuvo éxito con su institución, para la década de 1850, con un cuerpo docente de dos maestras (o preceptoras) que la acompañaron en sus labores, logró inscribirse en la Dirección General de Lima, luego de haber levantado favorablemente las observaciones que la misma institución le hizo. A éste hace referencia Reyes:

A mediados de la década el siglo XIX, aún funcionaba un colegio particular en la calle Carmen Bajo que se llamaba Sancho Dávila, y por la apariencia física de la directora, todo indica que era descendiente de la familia Sancho Dávila, antiguos marqueses de la Casa Dávila. ${ }^{21}$

En Lima ciudad, la cercanía de la ciudadanía acomodada, frente al gobierno central, pudo sobrellevarse, y tener cordiales relaciones. Sin embargo,

\footnotetext{
${ }^{20}$ Sin embargo, Echenique no terminó su período constitucional; pocos meses antes del final de su gobierno, se hizo público uno de los mayores escándalos sobre estafa y desfalco de las arcas públicas durante el siglo diecinueve. Y en ello, su debacle.

${ }^{21}$ Alejandro REYES, "Historia urbana de Lima: Los Barrios Altos, 1820-1880". Revista del Instituto de Investigaciones Sociales. Año VII. No 13, 2004, p. 159. Por cierto, la directora no es mencionada en los Almanaques de Lima, el del año 1851. Puede que su origen sea posterior al de esa fecha. Lo cual también nos prestaría algunas reflexiones, hasta ese año, se registraron pocos casos de acaudalados miembros de la sociedad peruana, quienes desearon (y concretaron) una educación distinta a la que ofrecían las instituciones públicas. Cabe recordar aquí la fundación del Colegio Nuestra Señora de Guadalupe, por Domingo Elías y el ciudadano español Nicolás Rodrigo, en 1840.
}

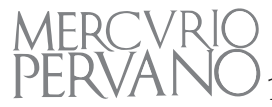


las justas exigencias al interior del país, fueron muy distintas. En 1851, el presidente Rufino Echenique nombró al P. Bartolomé Herrera como Director General de Instrucción. Fue el mismo Echenique quien nombró unos meses después al mismo Herrera como Ministro de Gobierno e Instrucción Pública. En el Calendario de 1852, la Junta Central de Instrucción Pública fue presidida por Agustín Guillermo Charún. La lista completa de los vocales de dicha Junta es la siguiente: Benito Lazo, Felipe Estenós, Buenaventura Seoane, José García Urrutia, Guillermo Carrillo, Luis E. Alvertini [sic], Manuel Villarán, Juan G. Menacho, José F. Naverrete, Miguel de los Ríos, Manuel V. Zeballos, José A. Rodulfo, Manuel Solari, Nicolás Piérola, y Francisco G. Prada. ${ }^{22}$ La presencia de Benito Lazo, así como la de Vicente Villarán, da indicios de una propuesta política en ciernes.

Ese mismo Calendario, anotó a José Francisco Navarrete bajo un cargo público notable, el de Inspector General de Establecimientos de Instrucción Primaria, este cargo, ya desde tiempos de Castilla, registró la remuneración mensual de quinientos pesos (500 Ps.) anuales. ${ }^{23}$ Como lo hemos mencionado anteriormente, la principal función del Inspector fue de visitar, observar y plantear al ejecutivo, informes constantes de los establecimientos de latinidad, así como los de instrucción primaria.

En agosto de 1851, a pocos meses del ascenso de Rufino Echenique como Presidente Constitucional del Perú, tomó la decisión de revocar el capítulo quinto de la flamante Ley de Instrucción Pública, decretada en los últimos meses de gobierno de su predecesor, Ramón Castilla. La principal causal en torno a la eliminación de dicha sección de la ley, fueron los constantes enfrentamientos entre las juntas de instrucción departamentales, seguramente, ante la Junta Central, en la ciudad de Lima. Entre los motivos expuestos en el mencionado decreto, debe notarse el fracaso en el intento de lograr la organización conjunta de la enseñanza. Además, los miembros de las juntas de instrucción se hallaban dedicados a otras ocupaciones, no pudiendo contraerse a las ocupaciones del ramo.

En definitiva, las numerosas corporaciones locales hicieron imposible proceder con rapidez y facilidad, los servicios y funciones propias que el Estado debía ejecutar. Aquí se halla el quid del asunto. A manera de propuesta abierta, estos fueron uno de los principales problemas a los que se enfrentaron estas juntas departamentales educativas:

- Ante los prefectos, representantes del poder ejecutivo en las provincias.

\footnotetext{
${ }^{22}$ Eduardo CARRASCO, Calendario y guía de forasteros de la República peruana, para el año bisiesto de 1852. Lima, Imprenta de Félix Moreno, 1851, p. 71.

${ }^{23}$ Ibid., p. 84.
} 
- Ante las juntas departamentales representativas, como entidad que manifestaba los reclamos y necesidades de los principales centros poblados del interior. Y entre ellas, lo hemos descrito anteriormente, se hallaba la exigencia popular de instalar colegios y escuelas en todos los poblados del país.

La creación de las juntas locales fue una medida enorme de Castilla en el avance de la educación nacional. Las juntas locales debieron tener un mejor diagnóstico de las falencias y necesidades de sus pueblos. Pero, sin un reglamento que los observase, existieron atribuciones que no fueron bien vistas desde Lima, máxime desde el gobierno central. Fue un juego político muy tirante entre los prefectos, la junta local educativa, y en tercer lugar el Estado central. Pudo haberse formulado una comisión, como lo hizo Castilla, para observar alguna ley o reglamento particular que limite las funciones de las juntas de instrucción del interior. Pero Echenique no lo hizo. Reiteramos, su legado sigue siendo funesto, y de oscuro accionar político, hasta hoy.

\section{A modo de conclusión}

A finales de la década de 1840, el clero fue cediendo paso, a medida que el gobierno tuvo los recursos para asumir su responsabilidad a plenitud. El Estado empezó a formar civiles especializados en el rubro, egresados de un centro de formación pedagógica, Ello ya fue posible a los pocos años de la declaración de la Independencia. El colegio de Santo Tomás, de la mano de su director José Francisco Navarrete, empezó una cruzada por la instrucción de los niños y jóvenes más necesitados de la ciudad. Sin recursos y medios, llevó a cabo un plan de instrucción lancasteriana desde la capital hasta los pueblos del interior del departamento. La mies era mucha, y los obreros pocos. Tuvo que esperarse hasta los inicios de la década de 1840, cuando ya se pudo contar con batallones de maestros, listos para iniciar la lucha contra el tenebroso manto de la ignorancia.

No fue sino hasta 1836, en los tiempos de la Confederación, en que el manejo de los fondos del ramo educativo tuvo un significativo avance en su administración y relativa autonomía. Visto desde los documentos, observo que la inestabilidad laboral de los maestros, en este caso de primeras letras, fue crítica. Hubo casos límite, en que a los maestros, por ejemplo, se les asignaba su sueldo mediante el arriendo estatal de una chacra a un tercero, de modo que lo cobraban (si podían) en forma directa. Los preceptores sólo podían acudir a la escuela central en pos de justicia, como una voz que pueda elevar su queja al Estado y hacer efectivos sus haberes correspondientes. En gran parte, la cristalización de la autonomía presupuestal, tuvo un gran impulso bajo el gobierno de Agustín Gamarra.

En 1846, el presidente constitucional Ramón Castilla, ordenó la conformación de una Comisión de Instrucción, encargada de elaborar un detallado informe sobre la educación pública. Si bien, la misma tuvo algunas

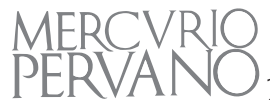


observaciones, como era el de centrarse principalmente en la problemática educacional de la ciudad capital, tuvo a bien elaborar un reglamento importante para la organización y conformación definitiva de la estructura educativa nacional. Ello también conllevó a otros problemas, el origen del centralismo político educativo en toda la nación. El poder ejecutivo fue a partir de 1850, el principal encargado de velar por la educación e instrucción de los niños y jóvenes de la nación.

Los gobiernos de Castilla y Echenique, particularmente, representaron el declive de los señores de la guerra. Con ellos, y gobiernos posteriores, se empezó a organizar y expandir la instrucción pública en el país. Con evidente centralismo institucional desde Lima. El Estado, al confirmar la aceptación general de la instrucción, accedió a fomentarla a nivel nacional.

La educación pública es un tema inconmensurable. Considero el presente artículo representa un aporte apropiado, una labor de apertura de trocha. La vida republicana echó a andar, y la educación era uno de sus principales bases de apoyo. El Estado, con todas sus carencias, no retiró ni dejó de apoyar la labor de educación e instrucción pública de sus ciudadanos.

\section{Anexo Documental ${ }^{24}$}

El Ciudadano Agustín Gamarra, Gran Mariscal Restaurador del Perú, benemérito de la patria en grado heroico y eminente, condecorado con las medallas del ejército Libertador, de Junín, Ayacucho, Ancash; con la de restaurador por el Congreso General, Generalísimo de las fuerzas de mar y tierra, Presidente Provisorio de la República, etc.

\section{MINISTERIO DE ESTADO EN EL DESPACHO DE INSTRUCCIÓN PÚBLI- CA, BENEFICENCIA, Y NEGOCIOS ECLESIÁSTICOS}

28 de febrero de 1840

\section{Separando de la administración de la Beneficencia las rentas de colegios y escuelas}

Considerando:

I. Que no pueden progresar los establecimientos públicos si se distrae en otros objetos las rentas que para su fomento les estén designadas.

II. Que tal inconveniente es un resultado necesario de la refusión [sic] en una sola masa de las rentas de Beneficencia y de Educación Pública.

\footnotetext{
${ }^{24}$ Este documento, así como el decreto ley número 8 de 1846 y el decreto supremo número 6 de 1850: Reglamento general de instrucción pública [ambos rubricados por el presidente Ramón Castilla], son accesibles ahora en el Archivo Digital de Legislación Peruana. Disponible en http://www.leyes.congreso.gob.pe/.
} 
Decreto:

Art. 01. Quedan separadas de la Administración de las rentas de Beneficencia las que corresponden a Colegios e Instrucción primaria.

Art. 02. Los administradores de Beneficencia entregarán a los Rectores y Directores de los margesíes, razón de deudas y demás documentos y existencias que les correspondan.

Art. 03. Los rectores de los Colegios y los Directores de Instrucción primaria recaudarán y administrarán las rentas de sus respectivos establecimientos, dando cada seis meses cuenta documentada de sus ingresos y egresos a los Prefectos, que la elevarán a Supremo Gobierno para su aprobación, o las devolverán con las observaciones correspondientes.

Art. 04. Los Prefectos suspenderán del ejercicio de su cargo, dando cuenta al Supremo Gobierno, al rector o Director que demorase, por más de ocho (08) días del término señalado, presentar sus cuentas o contestar a las observaciones de la Prefectura.

El Ministro de Estado en el Despacho de Instrucción Pública, Beneficencia y Negocios Eclesiásticos, queda encargado de su cumplimiento, mandándolo imprimir, publicar y circular.

Dado en la Casa del Supremo Gobierno, en Lima, a 28 de febrero de 1840.

[Fdo.] Agustín Gamarra.

Por orden de S.E.

[Fdo.] Agustín Guillermo Charún

\section{Referencias bibliográficas}

BASAdre, Jorge, Historia de la República del Perú. 7a. edición. Lima, Universitaria, 3 tomos, 1983.

CARrasco, Eduardo, Calendario y guía de forasteros de Lima para el año de 1841. Lima, Imprenta de Félix Moreno, 1841.

_- Calendario y guía de forasteros de la República peruana, para el año bisiesto de 1852. Lima, Imprenta de Félix Moreno, 1851.

Putnam, Jorge, Fundamentos teológicos de la actuación pública de Bartolomé Herrera. Tesis Doctoral. Pamplona, Universidad de Navarra, 2001.

REYEs, Alejandro, «Historia urbana de Lima: Los Barrios Altos, 1820-1880». En Rev.: Instituto de Investigaciones Sociales. Año VII. No. 13. Edit. Instituto de Investigaciones Históricos-Sociales. UNMSM. Lima-Perú, 2004.

Tilly, Charles, Democracia. Prólogo de Ramón Maiz. Madrid, AKAL, 2010.

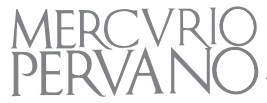

